NASA TECHNICAL NOTE

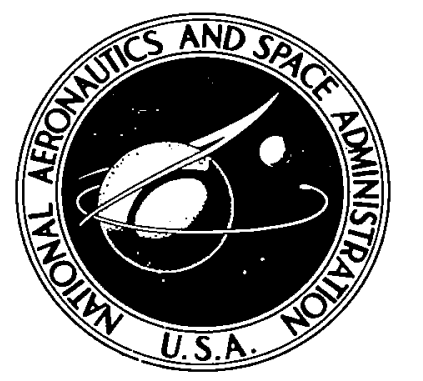

NASA IN D-6635

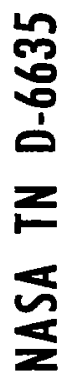

C. 1

LOAN COPY: RETU:

AFWL (DOUL" KIRTLAND AFB,

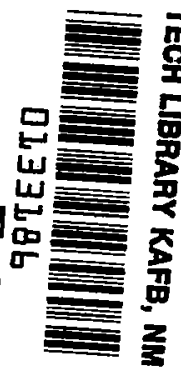

\title{
REFRACTIVE INDEX AND BIREFRINGENCE OF 2H SILICON CARBIDE
}

by J. Anthony Powell

Lewis Research Center

Cleveland, Obio 44135

NATIONAL AERONAUtics AND SPACE ADMINISTRATION - WASHINGTON, D. C. - JanUARY 1972 


\begin{tabular}{|c|c|}
\hline & 3. Recipient's Catalog No. \\
\hline \multirow{2}{*}{$\begin{array}{l}\text { 4. Title and Subtitle } \\
\text { REFRACTIVE INDEX AND BIREFRINGENCE OF 2H } \\
\text { SILICON CARBIDE }\end{array}$} & $\begin{array}{l}\text { 5. Report Date } \\
\text { January } 1972\end{array}$ \\
\hline & 6. Performing Organization Code \\
\hline $\begin{array}{l}\text { 7. Author(s) } \\
\text { J. Anthony Powell }\end{array}$ & $\begin{array}{l}\text { 8. Performing Organization Report No. } \\
\text { E-6476 }\end{array}$ \\
\hline \multirow{3}{*}{$\begin{array}{l}\text { 9. Performing Organization Name and Address } \\
\text { Lewis Research Center } \\
\text { National Aeronautics and Space Administration } \\
\text { Cleveland, Ohio } 44135\end{array}$} & $\begin{array}{l}\text { 10. Work Unit No. } \\
112-27\end{array}$ \\
\hline & 11. Contract or Grant No. \\
\hline & 13. Type of Report and Period Covered \\
\hline \multirow{2}{*}{$\begin{array}{l}\text { 12. Sponsoring Agency Name and Address } \\
\text { National Aeronautics and Space Administration } \\
\text { Washington, D.C. } 20546\end{array}$} & Technical Note \\
\hline & 14. Sponsoring Agency Code \\
\hline
\end{tabular}

\section{Abstract}

The refractive indices of $2 \mathrm{H} \mathrm{SiC}$ were measured over the wavelength range 435.8 to $650.9 \mathrm{~nm}$ by the method of minimum deviation. At the wavelength $\lambda=546.1 \mathrm{~nm}$, the ordinary index $\mathrm{n}_{0}$ was 2.6480 and the extraordinary index $n_{e}$ was 2.7237. The estimated error (standard deviation) in the measured values is 0.0006 for $n_{0}$ and 0.0009 for $n_{e}$. The experimental data were curve fitted to the Cauchy equation for the index of refraction as a function of wavelength. The birefringence of $2 \mathrm{H} \mathrm{SiC}$ was found to vary from 0.0719 at $\lambda=650.9 \mathrm{~nm}$ to 0.0846 at $\lambda=435.8 \mathrm{~nm}$.

17. Key Words (Suggested by Author(s))

Silicon carbide; Optical properties; Refractive index; Birefringence; Polytype; High temperature; Semiconductor; Dispersion; Crystal; Measurement

19. Security Classif. (of this report) Unclassified
20. Security Classif. (of this page) Unclassified
18. Distribution Statement

Unclassified - unlimited

* For sale by the National Technical Information Service, Springfield, Virginia 22151 


\title{
REFRACTIVE INDEX AND BIREFRINGENCE OF 2H SILICON CARBIDE
}

\author{
by J. Anthony Powell \\ Lewis Research Center
}

\section{SUMMARY}

Silicon carbide $(\mathrm{SiC})$ is a wide band gap semiconductor with much potential for high temperature applications. A major problem is that it forms many different crystalline structures, each with its own electrical and optical properties. This report presents the results of refractive index measurements on the simplest hexagonal structure, $2 \mathrm{H} \mathrm{SiC}$, over the wavelength range 435.8 to 650.9 nanometers. Measurements on the most common $\mathrm{SiC}$ structure, $6 \mathrm{H} \mathrm{SiC}$, are also reported and are in excellent agreement with previously published results. The method of minimum deviation was used in the measurements. The estimated error (standard deviation) in the measured values is 0.0006 for the ordinary index and 0.0009 for the extraordinary index. The systematic errors were considered to be small compared to the random errors in this estimate.

The experimental data were fitted to the Cauchy equation with the result that the ordinary index for $2 \mathrm{H} \mathrm{SiC}$ is given by

$$
\mathrm{n}_{\mathrm{o}}=2.5513+\frac{2.585 \times 10^{4}}{\lambda^{2}}+\frac{8.928 \times 10^{8}}{\lambda^{4}}
$$

and the extraordinary index is given by

$$
\mathrm{n}_{\mathrm{e}}=2.6161+\frac{2.823 \times 10^{4}}{\lambda^{2}}+\frac{11.490 \times 10^{8}}{\lambda^{4}}
$$

over the range of measurements when $\lambda$ is expressed in nanometers. The standard deviation of the experimental data from these equations is 0.0003 for $n_{0}$ and 0.0010 for $\mathrm{n}_{\mathrm{e}}$.

The birefringence of $2 \mathrm{H} \mathrm{SiC}$ was found to vary from 0.0719 at 650.9 nanometers to 0.0845 at 435.8 nanometers. These birefringence values are about 20 percent less than previously published data from retardation measurements on as-grown $2 \mathrm{H}$ SiC whiskers. The measured birefringence for $6 \mathrm{H} \mathrm{SiC}$ was in good agreement with previously published values. 


\section{INTRODUCTION}

Much effort has been spent over the years in an attempt to develop silicon carbide (SiC) as a high temperature semiconductor (refs. 1 and 2). A major problem is that SiC forms many different structures, called polytypes, each with its own electrical and optical properties (ref. 3). The various known SiC polytypes consist of a single cubic structure, called $\beta \mathrm{SiC}$, and many hexagonal and rhombohedral structures all of which are called $\alpha \mathrm{SiC}$.

The simplest hexagonal structure of $\mathrm{SiC}$ is the $2 \mathrm{H}$ polytype. This structure can be grown at $1400^{\circ} \mathrm{C}$ instead of $2500^{\circ} \mathrm{C}$ which is typical of the other $\alpha$ polytypes. This lower growth temperature would offer some advantages in the fabrication of semiconductor devices. However, the recent discovery (ref. 4) of a $2 \mathrm{H}$ to $\beta$ transformation above $1400^{\circ} \mathrm{C}$ casts doubt on the future of $2 \mathrm{H} \mathrm{SiC}$ as a useful high temperature semiconductor. Except for some absorption and luminescence measurements at low temperatures (ref. 5), very little has been published on the properties of $2 \mathrm{H} \mathrm{SiC.} \mathrm{The} \mathrm{main}$ reason is the small size of the crystals which have been grown.

Among the optical properties which vary with crystal structure is the refractive index. All of the SiC structures have an axis of hexagonal symmetry called the c-axis. Light passing through an $\alpha$ polytype in a direction other than along the c-axis will divide into two rays, each traveling with a different velocity. The ray with the electric vector perpendicular to the c-axis is called the ordinary ray, and the other ray with the electric vector parallel to the c-axis is called the extraordinary ray. In the case of $\mathrm{SiC}$, the ordinary ray travels faster so the ordinary refractive index $n_{0}$ will be less than the extraordinary refractive index $n_{e}$. The difference between the two refractive indices $\mathrm{n}_{\mathrm{e}}-\mathrm{n}_{\mathrm{o}}$ is the birefringence. This property also varies with polytype, and as will be demonstrated later, is a very useful property for examining the structure of SiC crystals (refs. 6 and 7).

Measurements of the refractive indices of several $\mathrm{SiC}$ polytypes have been reported previously. Thibault measured the indices for the $6 \mathrm{H}$ and $15 \mathrm{R}$ polytypes (ref. 8). Recently, Shaffer has reported measurements for the $\beta, 6 \mathrm{H}, 15 \mathrm{R}$, and $4 \mathrm{H}$ polytypes (ref. 9). Although he did not measure the refractive indices of $2 \mathrm{H}$, he did use the method of retardation to determine the birefringence of some as-grown $2 \mathrm{H}$ whiskers. Golightly has measured the birefringence of eleven SiC polytypes (not including $2 \mathrm{H}$ ) at one wavelength (ref. 10).

This report presents the results of refractive index measurements on $2 \mathrm{H}$ SiC over the wavelength range 435.8 to 650.9 nanometers. The results for $2 \mathrm{H}$ are then compared with the other common $\mathrm{SiC}$ polytypes. Measurements on $6 \mathrm{H} \mathrm{SiC}$ were also performed to check the experimental procedure. 

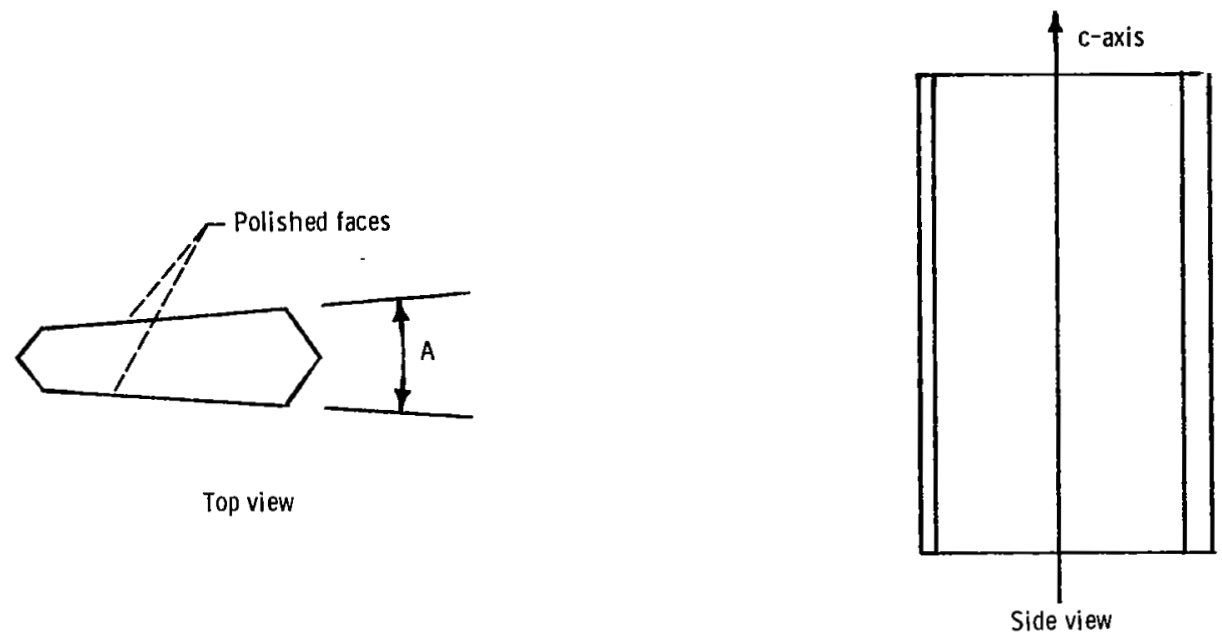

(a) Orientation of prisms with respect to c-axis.

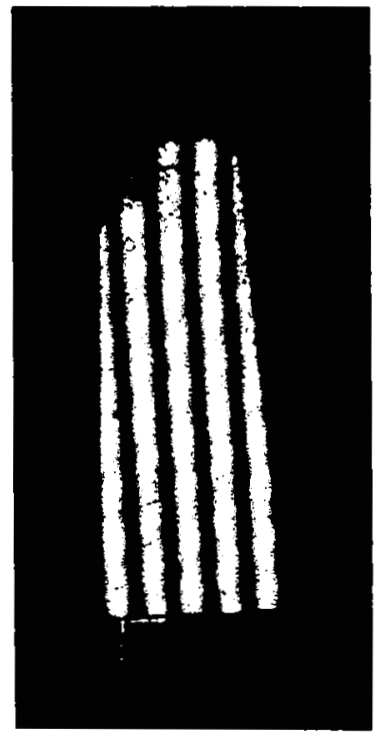

(b) Wedge 75-8.
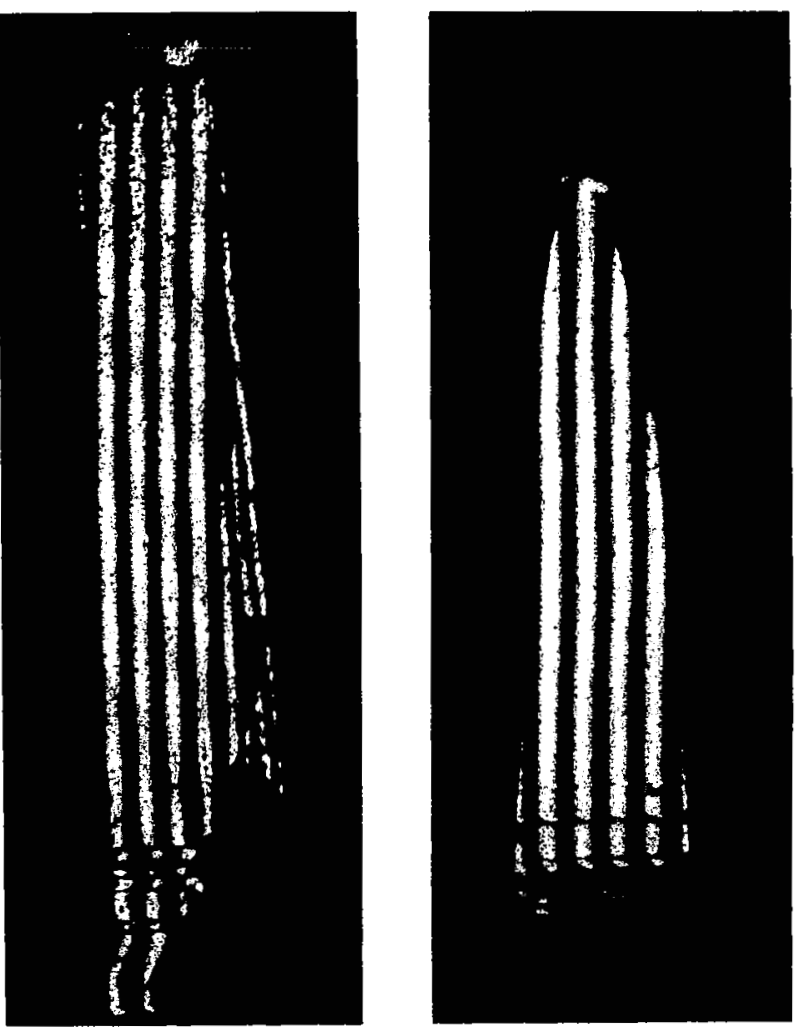

$1 \mathrm{~mm}$

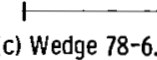

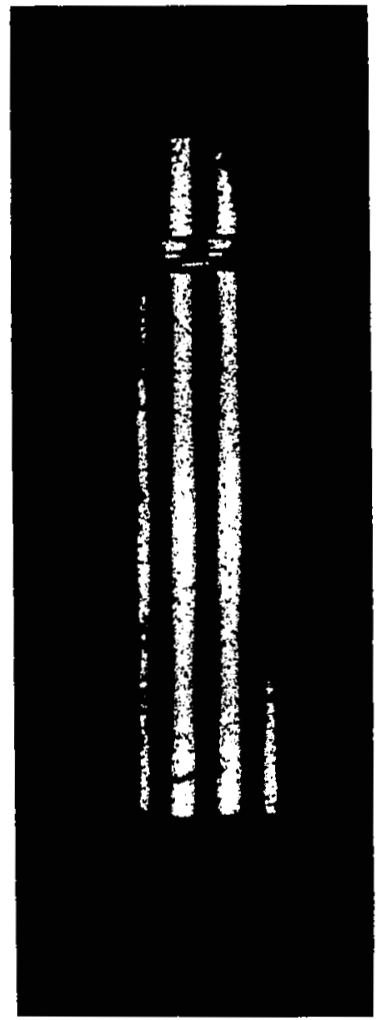

(e) Wedge 79-3.

Figure 1. - Photos showing interference fringes due to the birefringence in four $2 \mathrm{H}$ wedges. Wavelength, $\lambda=633$ nanometers. 


\section{PREPARATION OF PRISMS}

The method of crystal growth was similar to that reported previously (ref. 11). Hydrogen mixed with methyltrichlorosilane $\left(\mathrm{CH}_{3} \mathrm{SiCl}_{3}\right)$ was passed over an inductively heated graphite susceptor inside a quartz reaction tube. The $2 \mathrm{H} \mathrm{SiC}$ crystals grew on the susceptor at about $1400^{\circ} \mathrm{C}$ in the form of needles about 2 millimeters long with hexagonal cross sections about 0.4 millimeter in diameter.

Four $2 \mathrm{H} \mathrm{SiC} \mathrm{crystals} \mathrm{from} \mathrm{three} \mathrm{different} \mathrm{growth} \mathrm{runs} \mathrm{were} \mathrm{selected} \mathrm{and} \mathrm{made} \mathrm{into}$ prisms. A prism was also fabricated from a $6 \mathrm{H} \mathrm{SiC} \mathrm{crystal} \mathrm{which} \mathrm{had} \mathrm{been} \mathrm{grown} \mathrm{by}$ the usual sublimation process. The prism faces were prepared by grinding with diamond paste against a glass plate. The prism angles varied from $5.7^{\circ}$ to $8.8^{\circ}$. By means of an interference microscope, the prism faces were determined to be flat to better than one tenth of a wavelength $(\lambda=590 \mathrm{~nm})$.

The area of each polished face of the $6 \mathrm{H}$ prism was about twice that of the $2 \mathrm{H}$ prisms. Although all the prisms were clear and colorless, there were some regions of disorder in the $2 \mathrm{H}$ prisms. The four $2 \mathrm{H}$ prisms are shown in figure 1 along with a sketch showing the orientation of the prisms with respect to the crystal c-axis. The photographs were taken with the prisms placed between crossed polarizing filters and illuminated with monochromatic light (633-nm filter with a $1-\mathrm{nm}$ bandwidth). The interference fringes which are due to birefringence show the regions of stacking fault disorder present in each crystal. The birefringence varies over regions of stacking fault disorder so that the interference fringes take on a zigzag appearance (reg. 6). Prisms 79-2 and 79-3 are from the same growth run.

The structure of the four $2 \mathrm{H}$ prisms and the $6 \mathrm{H}$ prism was positively identified from c-axis $\mathrm{X}$-ray rotation photographs. These photographs were also used to observe stacking fault disorder. The presence of stacking faults is indicated by streaking on the X-ray photograph along the 10. $l$ reciprocal-lattice row of reflection spots (ref. 3 , p. 143). When the $\mathrm{X}$-ray beam was incident on regions of the prisms which were free of disorder as indicated by straight interference fringes in figure 1 , only a trace of disorder was observed on the $\mathrm{X}$-ray photograph.

\section{EXPERIMENTAL METHOD}

The method of minimum deviation was used to measure the refractive indices (ref. 12). Figure 2 illustrates the method and shows the light path through the measurement system. The prism is placed in a monochromatic collimated beam of light so that it deflects the beam by some angle $D$. The prism is then rotated about an axis parallel 


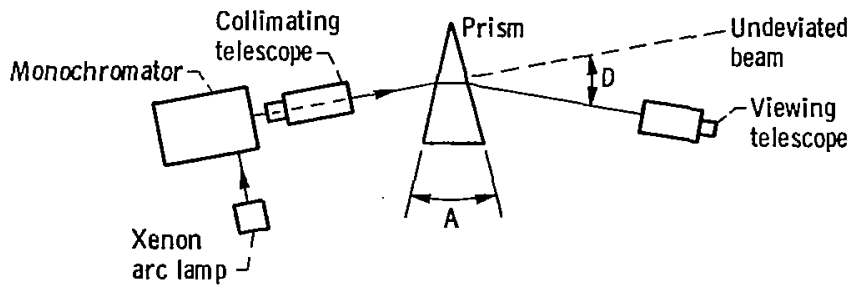

Figure 2. - Diagram showing light path through measurement system.

to the prism edge (an axis out of paper in fig. 2) until $D$ is a minimum. The refractive index $\mathrm{n}$ is then given by the expression

$$
\mathrm{n}=\frac{\sin \frac{A+D}{2}}{\sin \frac{A}{2}}
$$

where $A$ is the prism angle.

If the prism shown in figure 2 is rotated approximately $180^{\circ}$, there will be another position of minimum deviation on the other side of the undeviated beam. In this report, the angle $\mathrm{D}$ was taken as half the difference between these two angular positions of minimum deviation. Since $\mathrm{SiC}$ has two indices of refraction (one for the ordinary ray and one for the extraordinary ray), two angles of minimum deviation $D$ were determined for each wavelength.

As shown in figure 2, light from the 150-watt xenon arc lamp was passed through the grating monochromator and collimating telescope before striking the crystal prism. The exit slit of the monochromator was imaged at infinity by a focal adjustment of the collimating telescope, and then reimaged at the cross-hair reticle in the viewing telescope. The monochromator inlet and exit slits were set at 0.5 millimeter to produce a bandwidth of about 2 nanometers for $\mathbf{5 0}$ percent peak intensity at the band edges. A filter was used to eliminate most of the energy below 400 nanometers so that higher orders were not present in the wavelength range of measurement. Based on a calibration of the monochromator against the spectral lines in a mercury ( Hg) vapor lamp, the wavelengths in this report are correct to within 0.3 nanometer (standard deviation) of the actual value.

A precision dividing head was used to measure the angular positions of minimum deviation and the prism angles. It could be read to better than 1 second of arc and was accurate to within 1 second of arc. In figure 3 , the apparatus is shown set up to measure the minimum deviation angle. The viewing telescope was bolted to the rotating table of the dividing head. A rotating microscope stage, which was used to rotate the prism, 


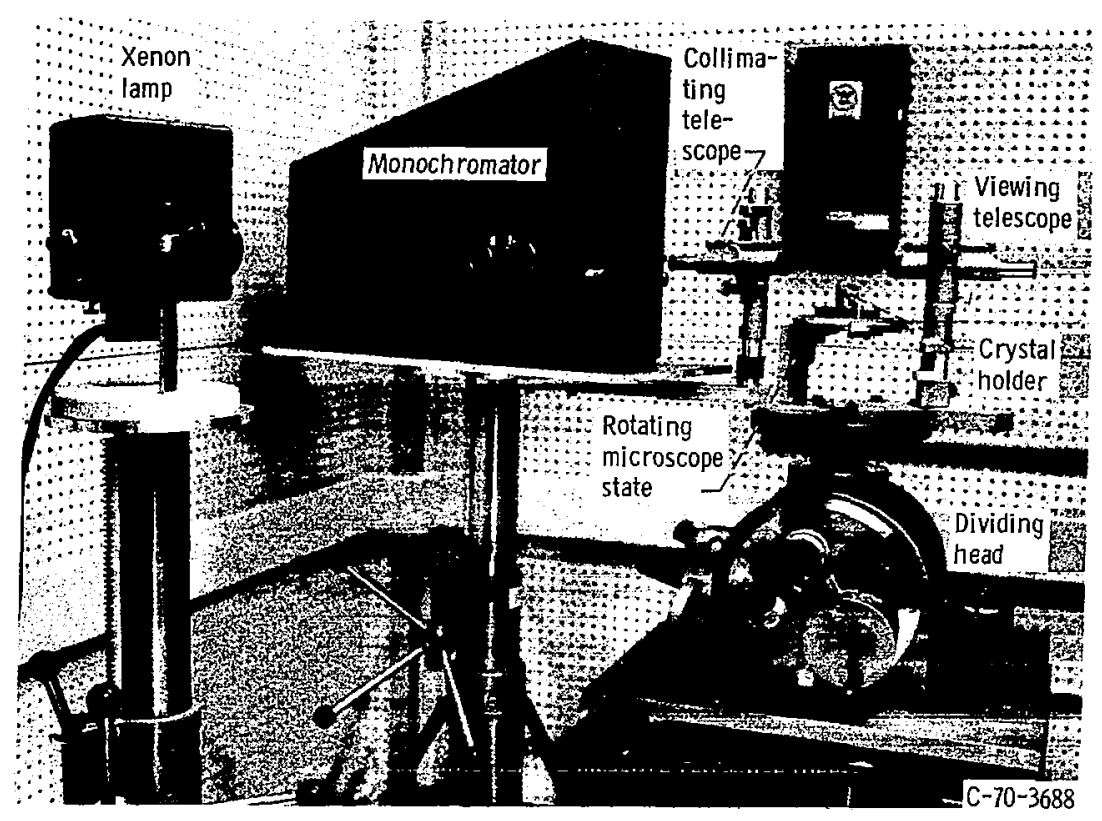

Figure 3. - Apparatus used to measure refractive index.

was also mounted on the dividing head table. The rotation axes of the dividing head and microscope stage were coincident and vertical. The crystal holder was adjustable such that the prisms could be positioned in the center of the rotation axis with the polished prism faces vertical. A horizontal He-Ne laser beam reflecting off the polished prism faces was helpful in orienting the prisms so that the faces were exactly vertical. This laser was also used in alining the optics when setting up the apparatus.

The viewed images of the monochromator slit for the ordinary and extraordinary rays were clear and distinct for all five prisms. The ordinary image was distinguished from the extraordinary image with the aid of a polarizing filter. During measurement, the c-axis of each prism was nearly vertical so the ordinary image was horizontally polarized and the extraordinary image was vertically polarized. At each position of minimum deviation at least two angle readings were made and these readings were then averaged. The standard deviation of the readings from the respective averages was less than 8 seconds of arc for all the prisms.

In making the prism angle measurements, the viewing telescope was mounted on a cathetometer stand instead of the dividing head table. In this measurement the collimated beam from the monochromator was reflected off each polished prism face in turn and into the viewing telescope. The prism angle was then determined from the two dividing head angles corresponding to each prism face. Each of these angles was the average of six readings. The standard deviations of these readings from the averages was less than 7 seconds of arc for all the prisms. 


\section{MISALINEMENT OF THE C-AXIS}

Because of the difficulty in orienting the crystals during the grinding of the prism faces, the bisecting plane of the fabricated prisms was not parallel to the crystal c-axis. This caused an error in the measured extraordinary (but not the ordinary) refractive index (ref. 12). This error was corrected after the angle $\Delta_{1}$ between the c-axis and the bisecting plane was determined for each of the prisms. An optical method was used to determine $\Delta_{1}$.

The optical method was as follows. Normally, the crystals were broken from the susceptor along a flat cleavage surface which was shown to be the basal plane (the plane perpendicular to the c-axis) by $\mathrm{X}$-ray diffraction. The angle $\Delta_{1}$ was determined by measuring the angle which each polished face made with the basal plane (see fig. 4). It can be shown that

$$
\Delta_{1}=\arcsin \frac{\cos \theta_{2}-\cos \theta_{1}}{2 \cos \frac{A}{2}}
$$

where $\theta_{1}$ and $\theta_{2}$ are the two angles which the two polished faces make with the basal plane and $A$ is the prism angle.

By properly orienting the prism on the dividing head and reflecting a He-Ne laser beam off two faces in turn and back to some fixed reference point, the angle between the

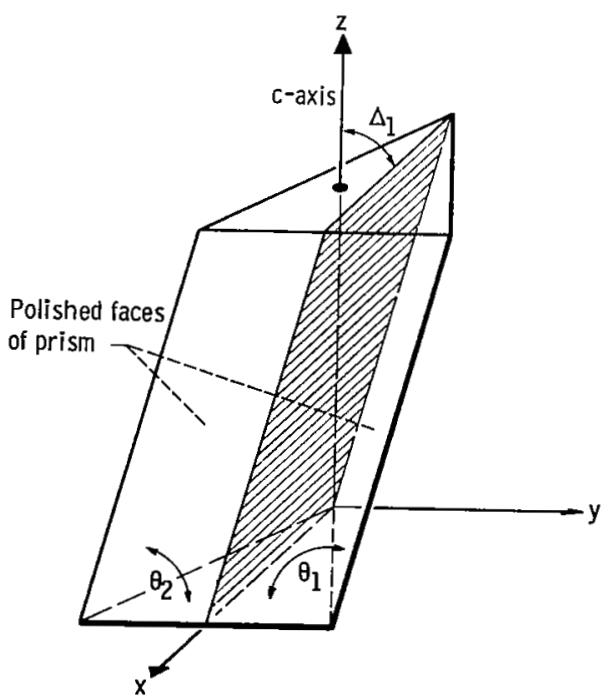

Figure 4. - Diagram showing angles $\theta_{1}$ and $\theta_{2}$ which prism faces make with basal plane. (The c-axis is perpendicular to basal plane which is in $x-y$ plane.) 
two faces can be determined. With this method, $\theta_{1}$ and $\theta_{2}$ were measured for each prism with an error of less than 5 minutes of arc.

In addition to identifying the crystal prisms as $2 \mathrm{H} \mathrm{SiC}$, the $\mathrm{X}$-ray rotation photographs were used to show that the c-axis was perpendicular to the cleavage plane. When taking an $\mathrm{X}$-ray rotation photograph with $\mathrm{c}$-axis not alined with the $\mathrm{X}$-ray camera rotation axis, the resulting reflecting spots from crystallographically equivalent planes in the crystal lattice do not coincide. In this case, multiple spots appear on the X-ray film.

With a prism in the $X$-ray camera, its orientation was adjusted with respect to the camera rotation axis until single spots from equivalent planes were obtained on the film. If the c-axis were indeed perpendicular to the cleavage plane, then the angle which the thin prism made with the rotation axis would be equal to the angle $\Delta_{1}$ measured with the optical method. The two angles were equal for every prism to within the precision of the measurement which was about 15 minutes of arc.

The true value of the extraordinary refractive index $\mathrm{n}_{\mathrm{e}}$ was calculated from the expression (ref. 12)

$$
\mathrm{n}_{\mathrm{e}}^{-2}=\mathrm{n}_{\mathrm{em}}^{-2}-\Delta_{1}^{2} \mathrm{n}_{\mathrm{o}}^{-2}
$$

where $\mathrm{n}_{\mathrm{em}}$ is the measured extraordinary refractive index. The amount of correction ranged from 0.0017 to 0.0046 for the $2 \mathrm{H}$ prisms and was 0.0006 for the $6 \mathrm{H}$ prism.

\section{RESULTS}

The results for the $2 \mathrm{H}$ prisms are given in table I. The two sets of 28 data points representing the four prisms at seven wavelengths were fitted to the Cauchy equation (ref. 13)

$$
\mathrm{n}=\mathrm{a}+\frac{\mathrm{b}}{\lambda^{2}}+\frac{\mathrm{c}}{\lambda^{4}}
$$

The curve fit yielded

$$
\mathrm{n}_{\mathrm{o}}=2.5513+\frac{2.585 \times 10^{4}}{\lambda^{2}}+\frac{8.928 \times 10^{8}}{\lambda^{4}}
$$


TABLE I. - REFRACTIVE INDEX DATA FOR FOUR

2H SiC CRYSTALS

\begin{tabular}{|c|c|c|c|c|c|}
\hline \multirow{2}{*}{$\begin{array}{c}\text { Wave- } \\
\text { length, } \\
\lambda, \\
\text { nm }\end{array}$} & \multicolumn{4}{|c|}{ Prisms } & \multirow{2}{*}{$\begin{array}{c}\text { Calculated } \\
\text { values }^{\mathrm{a}}\end{array}$} \\
\hline & $75-8$ & $78-6$ & $79-2$ & $79-3$ & \\
\hline \multicolumn{6}{|c|}{ Ordinary ray, $n_{0}$} \\
\hline 435.8 & 2. 7122 & 2.7118 & 2.7123 & 2.7121 & 2.7121 \\
\hline 450.3 & 2. 7006 & 2. 7004 & 2. 7009 & 2. 7002 & 2.7005 \\
\hline 500.7 & 2. 6684 & 2.6684 & 2. 6691 & 2.6687 & 2.6686 \\
\hline 546.1 & 2. 6479 & 2. 6478 & 2. 6486 & 2. 6475 & 2.6480 \\
\hline 551. 1 & 2. 6458 & 2. 6458 & 2. 6463 & 2.6464 & 2.6461 \\
\hline 601.5 & 2. 6295 & 2. 6296 & 2. 6298 & 2. 6291 & 2.6295 \\
\hline 650.9 & 2. 6173 & 2. 6172 & 2.6175 & 2. 6167 & 2.6173 \\
\hline \multicolumn{6}{|c|}{ Extraordinary ray, $\mathrm{n}_{\mathrm{e}}$} \\
\hline 435.8 & 2. 7962 & 2. 7963 & 2.7980 & 2. 7956 & 2. 7966 \\
\hline 450.3 & 2.7832 & 2.7832 & 2.7848 & 2.7823 & 2.7833 \\
\hline 500.7 & 2. 7467 & 2.7468 & 2. 7488 & 2. 7462 & 2. 7470 \\
\hline 546.1 & 2. 7233 & 2. 7237 & 2. 7253 & 2. 7225 & 2. 7237 \\
\hline 551.1 & 2. 7210 & 2.7213 & 2.7228 & 2.7212 & 2.7215 \\
\hline 601.5 & 2. 7022 & 2. 7028 & 2. 7041 & 2. 7012 & 2.7029 \\
\hline 650.9 & 2. 6885 & 2. 6890 & 2. 6909 & 2. 6876 & 2.6892 \\
\hline
\end{tabular}

TABLE II. - BIREFRINGENCE

OF $2 \mathrm{H} \mathrm{SiC} \mathrm{(FROM} \mathrm{CALCU-}$

LATED VALUES OF

TABLE I)

\begin{tabular}{|c|c|}
\hline $\begin{array}{c}\text { Wavelength, } \\
\lambda, \\
n m\end{array}$ & $\begin{array}{c}\text { Birefringence, } \\
\delta\end{array}$ \\
\hline 435.8 & 0.0845 \\
450.3 & .0828 \\
500.7 & .0784 \\
546.1 & .0757 \\
551.1 & .0754 \\
601.5 & .0734 \\
650.9 & .0719 \\
\hline
\end{tabular}

avalues obtained from a curve fit.

and

$$
n_{e}=2.6161+\frac{2.823 \times 10^{4}}{\lambda^{2}}+\frac{11.490 \times 10^{8}}{\lambda^{4}}
$$

where $\lambda$ is expressed in nanometers.

The indices in the last column of table I were calculated from these two equations. The standard deviation of the experimental values from the calculated values is 0.0003 for $n_{0}$ and 0.0010 for $n_{e}$. The birefringence values obtained from the calculated values of $n_{e}$ and $n_{0}$ are listed in table $\Pi$.

The results for the $6 \mathrm{H}$ prism are given in table $\mathrm{III}$. The two sets of seven experimental values were fitted to the Cauchy equation with the result that

$$
n_{0}=2.5617+\frac{2.721 \times 10^{4}}{\lambda^{2}}+\frac{9.235 \times 10^{8}}{\lambda^{4}}
$$


TABLE III. - REFRACTIVE INDEX VALUES

FOR $6 \mathrm{H} \mathrm{SiC}$

\begin{tabular}{|c|c|c|c|c|}
\hline \multirow{2}{*}{$\begin{array}{c}\text { Wave- } \\
\text { length, } \\
\lambda, \\
\mathrm{nm}\end{array}$} & \multicolumn{2}{|c|}{ Author's data } & \multirow{2}{*}{$\begin{array}{c}\text { Thibault's } \\
\text { data } \\
\text { (ref. 8) }\end{array}$} & \multirow{2}{*}{$\begin{array}{c}\text { Shaffer's } \\
\text { data } \\
\text { (ref. 9) }\end{array}$} \\
\hline & $\begin{array}{l}\text { Experi- } \\
\text { mental }\end{array}$ & $\begin{array}{l}\text { Calcu- } \\
\text { lated }^{a}\end{array}$ & & \\
\hline \multicolumn{5}{|c|}{ Ordinary ray, $\mathrm{n}_{\mathrm{o}}$} \\
\hline 435.8 & 2.7306 & 2.7305 & 2.7305 & ----- \\
\hline 450.3 & 2.7182 & 2.7183 & ----- & ----- \\
\hline 467.0 & ------ & 2.7058 & ----- & 2.7074 \\
\hline 498.0 & $-\ldots--$ & 2.6864 & ----- & 2.6870 \\
\hline 500.7 & 2. 6849 & 2.6849 & $-\ldots--$ & 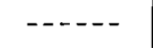 \\
\hline 515.0 & ----- & 2.6774 & ----- & 2.6789 \\
\hline 546.1 & 2.6634 & 2.6633 & 2.6631 & $\ldots-\ldots$ \\
\hline 551.1 & 2.6612 & 2. 6613 & ------ & $-\ldots-$ \\
\hline 568.0 & $---\cdots$ & 2.6549 & ------ & 2.6557 \\
\hline 578.1 & $\ldots \ldots$ & 2.6514 & 2.6511 & ----- \\
\hline 589.0 & ---- & 2.6478 & 2.6475 & 2.6488 \\
\hline 601.5 & 2.6439 & 2. 6439 & ----- & ----- \\
\hline 616.0 & ----- & 2.6398 & ----- & 2.6411 \\
\hline 650.9 & 2.6309 & 2. 6310 & ----- & $-\cdots--$ \\
\hline \multicolumn{5}{|c|}{ Extraordinary ray, $\mathrm{n}_{\mathrm{e}}$} \\
\hline 435.8 & 2.7831 & 2.7829 & 2.7824 & ------ \\
\hline 450.3 & 2.7686 & 2.7689 & ------ & 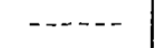 \\
\hline 467.0 & ----- & 2.7547 & $\ldots-\cdots$ & 2.7553 \\
\hline 498.0 & $\ldots . .$. & 2. 7327 & $-\ldots$ & 2. 7331 \\
\hline 500.7 & 2.7310 & 2. 7311 & $\ldots-\ldots$ & ----- \\
\hline 515.0 & $-\cdots--$ & 2.7227 & ----- & 2.7236 \\
\hline 546.1 & 2.7072 & 2.7070 & 2. 7064 & $-\cdots--$ \\
\hline 551.1 & 2. 7049 & 2.7048 & ------ & ----- \\
\hline 568.0 & ----- & 2. 6978 & ----- & 2.6979 \\
\hline 578.1 & ------ & 2.6939 & 2.6933 & $-\cdots---$ \\
\hline 589.0 & ----- & 2.6900 & 2.6889 & 2.6911 \\
\hline 601.5 & 2.6857 & 2.6858 & ------ & 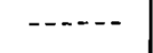 \\
\hline 616.0 & ----- & 2.6813 & ----- & 2.6820 \\
\hline 650.9 & 2.6714 & 2. 6719 & $\ldots \ldots$ & $\ldots---$ \\
\hline
\end{tabular}

avalues obtained from curve fit of author's data. 
and

$$
n_{e}=2.6001+\frac{2.694 \times 10^{4}}{\lambda^{2}}+\frac{14.773 \times 10^{8}}{\lambda^{4}}
$$

when $\lambda$ is expressed in nanometers. The indices in the third column of table III were calculated from these equations.

In estimating the error in the measured values of the index of refraction the systematic errors were considered to be small compared to the random errors. On this basis, the estimated error (standard deviation) for both $2 \mathrm{H}$ and $6 \mathrm{H} \mathrm{SiC} \mathrm{is} 0.0006$ for $\mathrm{n}_{\mathrm{o}}$ and 0.0009 for $n_{e}$.

The additional wavelengths listed in tables III and IV are those for which Thibault (ref. 8) and Shaffer (ref. 9) have published values for $6 \mathrm{H} \mathrm{SiC.} \mathrm{As} \mathrm{can} \mathrm{be} \mathrm{seen} \mathrm{there} \mathrm{is}$ excellent agreement among the three sets of data. The difference between any two values at any given wavelength is less than the sum of the estimated errors in the two values.

TABLE IV. - BIREFRINGENCE VALUES

ᄀOR $6 \mathrm{H} \mathrm{SiC}$

[Calculated from data in table III.]

\begin{tabular}{|c|c|c|c|c|}
\hline \multirow{2}{*}{$\begin{array}{c}\text { Wave- } \\
\text { length, } \\
\lambda, \\
\mathrm{nm}\end{array}$} & \multicolumn{2}{|c|}{ Author's data } & \multirow{2}{*}{$\begin{array}{c}\text { Thibault's } \\
\text { data } \\
\text { (ref. } 8 \text { ) }\end{array}$} & \multirow{2}{*}{$\begin{array}{c}\text { Shaffer's } \\
\text { data } \\
\text { (ref. 9) }\end{array}$} \\
\hline & $\begin{array}{l}\text { Experi- } \\
\text { mental }\end{array}$ & $\begin{array}{c}\text { Calcu- } \\
\text { lated }\end{array}$ & & \\
\hline 435.8 & 0.0525 & 0.0524 & 0.0519 & ----- \\
\hline 450.3 & .0504 & .0506 & $---\ldots$ &.---- \\
\hline 467.0 & $-\ldots---$ & .0489 &.---- & 0.0479 \\
\hline 498.0 & $\ldots-\cdots$ & 0.0463 & ------ & 0.0461 \\
\hline 500.7 & 0.0461 & .0462 & ----- & $---\cdots$ \\
\hline 515.0 & ---- & .0453 & -.... & .0447 \\
\hline 546.1 & 0.0438 & 0.0437 & 0.0433 & $----n$ \\
\hline 551.1 & .0437 & .0435 &.---- & ---- \\
\hline 568.0 & $---\cdots$ & .0429 & 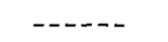 & 0.0422 \\
\hline 578.1 & $-\cdots$ & 0.0425 & 0.0422 & 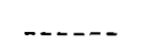 \\
\hline 589.0 & ---- & .0422 & .0414 & 0.0423 \\
\hline 601.5 & 0.0418 & .0419 & ---- & 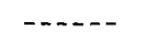 \\
\hline 616.0 & ----- & 0.0415 & $--\ldots$ & 0.0409 \\
\hline 650.9 & 0.0405 & .0409 & $---\cdots$ & $---\infty$ \\
\hline
\end{tabular}


Birefringence values for $6 \mathrm{H} \mathrm{SiC}$, obtained from the refractive indices in table $\mathrm{III}$, are shown in table IV. The author's values are slightly higher than those of Thibault and Shaffer.

\section{DISCUSSION}

Despite the small size of the prisms, the experimental procedure apparently yielded accurate results. The data for the $6 \mathrm{H} \mathrm{SiC} \mathrm{prism} \mathrm{is} \mathrm{in} \mathrm{excellent} \mathrm{agreement} \mathrm{with} \mathrm{the} \mathrm{pre-}$ viously published results. Also, the deviation of the experimental data from the calculated curve was small.

The variation of refractive index with wavelength (dispersion) of $2 \mathrm{H} \mathrm{SiC}$ is plotted in figure 5, based on the calculated values in table $\mathrm{I}$. Also plotted are the dispersion curves for $\beta, 6 \mathrm{H}, 4 \mathrm{H}$, and $15 \mathrm{R} \mathrm{SiC}$ from reference 9 . As can be seen, the ordinary index for $2 \mathrm{H}$ is less than all the other SiC polytypes.

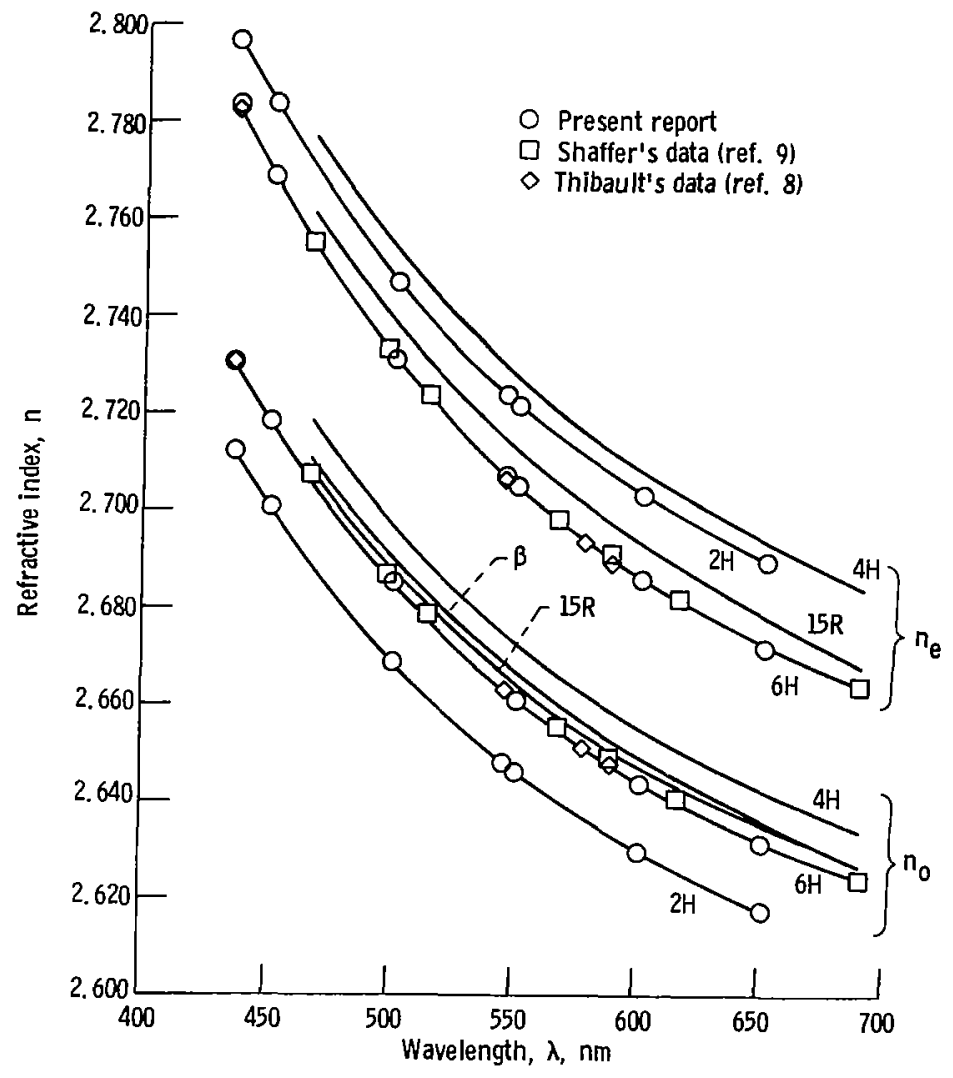

Figure 5. - Dispersion of SiC polytypes. Data points included for $2 \mathrm{H}$ and $6 \mathrm{H}$ curves only. The $\mathrm{B}, 4 \mathrm{H}$, and $15 \mathrm{R}$ curves are from Shaffer (ref. 9). 
In figure 6 , the birefringence, $\delta$, for $2 \mathrm{H}, 4 \mathrm{H}, 6 \mathrm{H}$, and $15 \mathrm{R}$ is plotted as a function of wavelength. As can be seen, the values of $\delta(6 \mathrm{H})$ as measured by the author, Thibault, and Shaffer all lie essentially on the same curve. However, the author's values for $2 \mathrm{H} \mathrm{SiC}$ are significantly lower than those measured by Shaffer. His data for $2 \mathrm{H} \mathrm{SiC}$ were obtained from retardation measurements on a whisker and no estimate in the experimental error was given. The birefringence values for the other polytypes are all from refractive index measurements.

There have been attempts to relate the birefringence of SiC to the crystal structure. In the $\mathrm{ABC}$. . . sequence notation of SiC polytypes (ref. 3), any particular double layer of $\mathrm{Si}$ and $\mathrm{C}$ atoms (perpendicular to the $\mathrm{c}$-axis) can be considered to be either cubic or hexagonal. In this notation the sequence for $2 \mathrm{H} \mathrm{SiC}$ is $\mathrm{ABAB} \ldots$. . that for $\beta \mathrm{SiC}$ is $\mathrm{ABCABC}$. . . , that for $4 \mathrm{H}$ is $\mathrm{ABACABAC}$. . . , and so on. A double layer is considered to be cubic if the two adjoining double layers have different orientations and considered to be hexagonal if the two adjoining double layers have the same orientation. For each polytype, the fraction of hexagonal layers $h$ can be computed.

In the structurally analogous system of zinc sulfide polytypes, the birefringence is a linear function of the hexagonal fraction (ref. 14). The situation for SiC is not so simple.

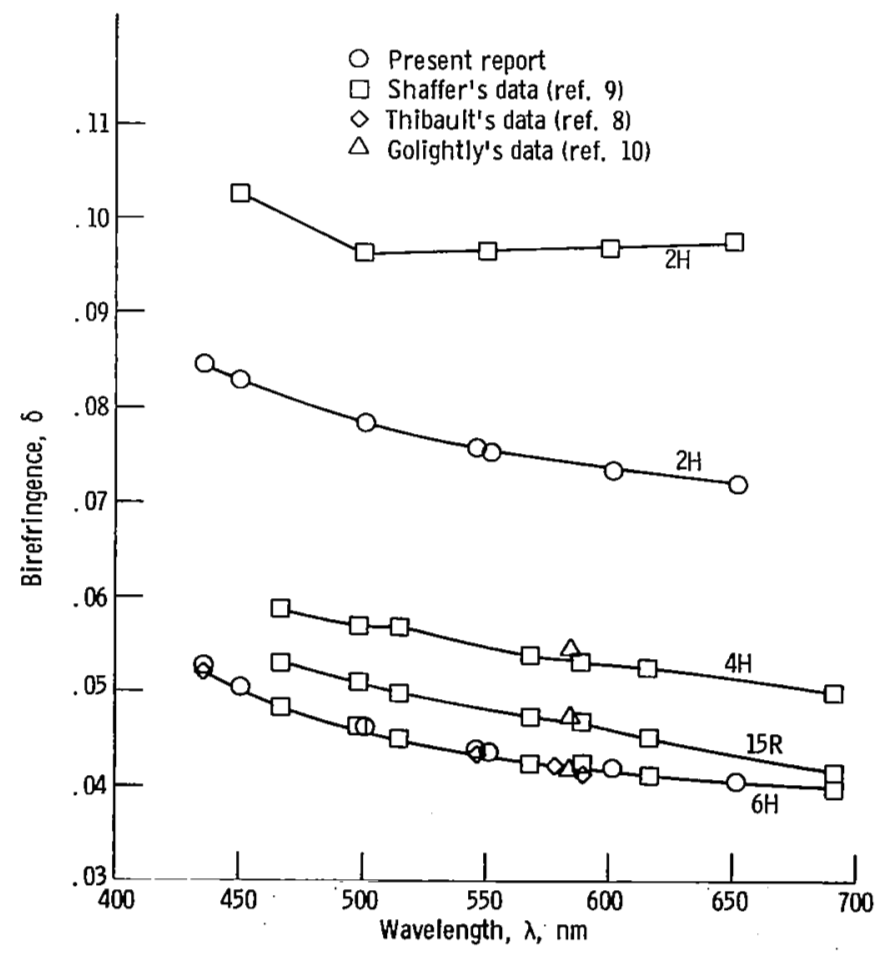

Figure 6. - Birefringence plotted against wavelength of SiC polytypes. 
Golightly measured the birefringence of a number of SiC polytypes for $\lambda=584$ nanometers (ref. 10). He used an interference fringe method in thin prisms cut from syntactically intergrown polytypes. Some of his results are listed in table V. The birefringence for $2 \mathrm{H}, \delta(2 \mathrm{H})$, was calculated from the equations for $\mathrm{n}_{\mathrm{o}}$ and $\mathrm{n}_{\mathrm{e}}$ for $\lambda=584$ nanometers. These values for $\delta$ are plotted as a function of the hexagonal frac-

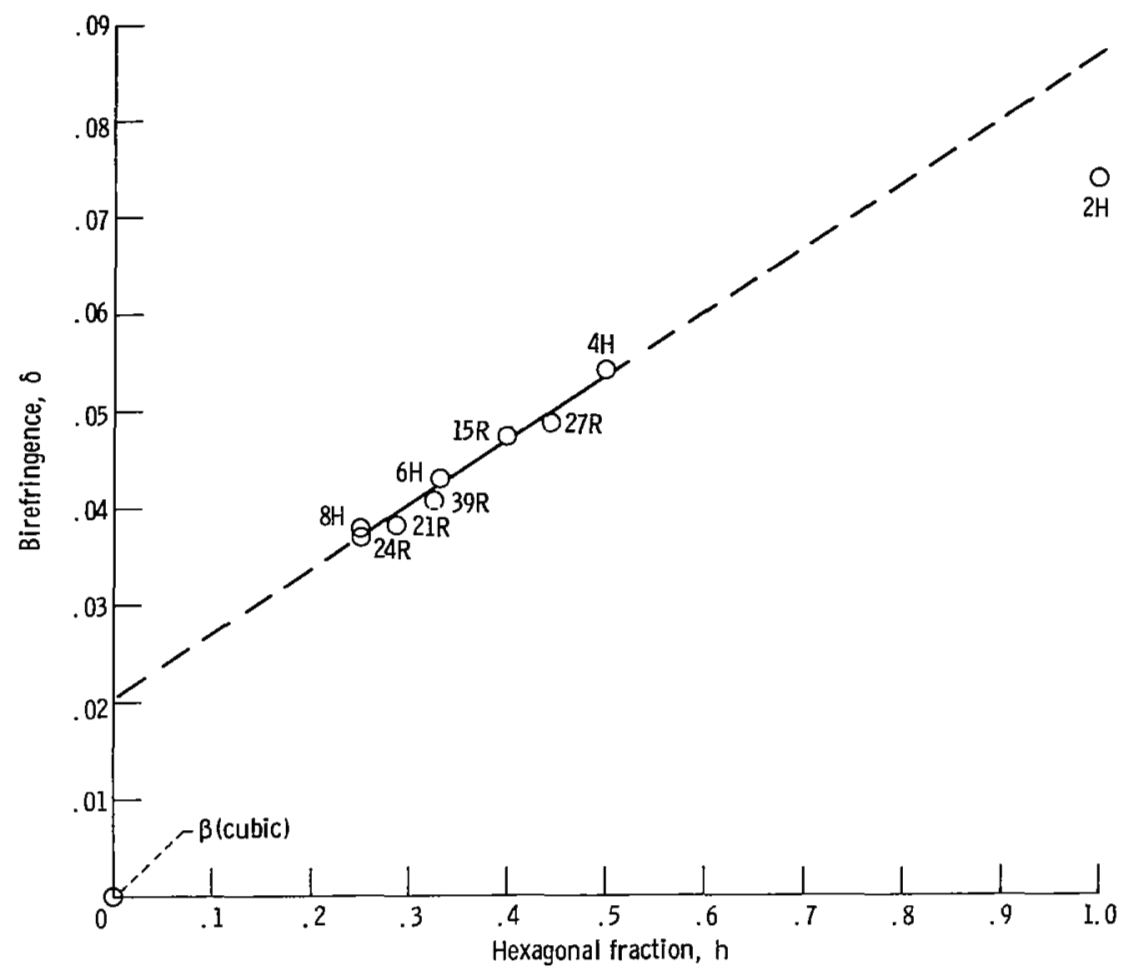

Figure 7. - Birefringence plotted against hexagonal fraction of $\mathrm{SiC}$ polytypes at wavelength $\lambda=584$ nanometers. (All values except for $2 \mathrm{H}$ are from Golightly (ref. 10).)

TABLE V. - BIREFRINGENCE OF SiC POLYTYPES AT

WAVELENGTH $\lambda=584$ NANOMETERS

[All values except for $2 \mathrm{H}$ are from ref. 10.]

\begin{tabular}{|l|c|c|c|c|c|}
\hline Polytype & $\begin{array}{c}\text { Birefrin- } \\
\text { gence, } \\
\delta\end{array}$ & $\begin{array}{c}\text { Hexagonal } \\
\text { fraction, } \\
\mathrm{h}\end{array}$ & Polytype & $\begin{array}{c}\text { Birefrin- } \\
\text { gence, } \\
\delta\end{array}$ & $\begin{array}{c}\text { Hexagonal } \\
\text { fraction, } \\
\mathrm{h}\end{array}$ \\
\hline$\beta$ & 0 & 0 & $6 \mathrm{H}$ & 0.043 & 0.333 \\
$8 \mathrm{H}$ & .0377 & .25 & $15 \mathrm{R}$ & .0474 & .400 \\
$24 \mathrm{R}$ & .0369 & .25 & $27 \mathrm{R}$ & $.0488 \pm 0.0004$ & .445 \\
$21 \mathrm{R}$ & .0382 & .286 & $4 \mathrm{H}$ & $.0543 \pm 0.0023$ & .500 \\
$39 \mathrm{R}$ & .0408 & .325 & $2 \mathrm{H}$ & .0739 & 1.000 \\
\hline
\end{tabular}


tion in figure 7 . For $h$ between 0.25 and $0.50, \delta$ is a linear function of the hexagonal fraction. As can be seen $\delta(\beta)$ and $\delta(2 \mathrm{H})$ lie considerably below this line.

\section{SUMMARY OF RESULTS}

The refractive indices of $2 \mathrm{H}$ and $6 \mathrm{H}$ SiC were measured over the wavelength range 435. 8 to 650.9 nanometers. The estimated error (standard deviation) in the measured values is 0.0006 for the ordinary index $n_{0}$ and 0.0009 for the extraordinary index $n_{e}$. A curve fit of the $2 \mathrm{H}$ data to the Cauchy equation yielded the result that

$$
\mathrm{n}_{\mathrm{o}}=2.5513+\frac{2.585 \times 10^{4}}{\lambda^{2}}+\frac{8.928 \times 10^{8}}{\lambda^{4}}
$$

and

$$
n_{e}=2.6161+\frac{2.823 \times 10^{4}}{\lambda^{2}}+\frac{11.490 \times 10^{8}}{\lambda^{4}}
$$

when $\lambda$ is expressed in nanometers. The standard deviation of the experimental data from these equations is 0.0003 for $n_{0}$ and 0.0010 for $n_{e}$.

A curve fit of the $6 \mathrm{H}$ data to the Cauchy equation yielded the result that

$$
n_{0}=2.5617+\frac{2.721 \times 10^{4}}{\lambda^{2}}+\frac{9.235 \times 10^{8}}{\lambda^{4}}
$$

and

$$
\mathrm{n}_{\mathrm{e}}=2.6001+\frac{2.694 \times 10^{4}}{\lambda^{2}}+\frac{14.773 \times 10^{8}}{\lambda^{4}}
$$

when $\lambda$ is expressed in nanometers. Refractive indices calculated from these two expressions are in excellent agreement with previously published results for $6 \mathrm{H} \mathrm{SiC}$.

The birefringence of $2 \mathrm{H} \mathrm{SiC}$ was found to vary from 0.0719 at 650.9 nanometers to 0.0845 at 435.8 nanometers. These birefringence values are about 20 percent less than previously published data from retardation measurements on as-grown $2 \mathrm{H}$ SiC whiskers. 
The measured birefringence for $6 \mathrm{H}$ SiC was in good agreement with previously published values.

Lewis Research Center,

National Aeronautics and Space Administration,

Cleveland, Ohio, November 4, 1971,

112-27.

\section{REFERENCES}

1. O'Connor, J. R.; and Smiltens, J., eds.: Silicon Carbide; A High Temperature Semiconductor. Pergamon Press, 1960.

2. Henisch, H. K.; and Roy, R., eds.: Silicon Carbide - 1968. Proceedings of the International Conference on Silicon Carbide. Pergamon Press, 1969.

3. Verma, Ajit R.; and Krishna, P.: Polymorphism and Polytypism in Crystals. John Wiley \& Sons, Inc., 1966.

4. Krishna, P.; Marshall, R. C. ; and Ryan, C. E.: The Discovery of a 2H-3C Solid State Transformation in Silicon Carbide Single Crystals. J. Crystal Growth, vol. 8, no. 1, Jan. 1971, pp. 129-131.

5. Patrick, Lyle; Hamilton, D. R.; and Choyke, W. J.: Growth, Luminescence, Selection Rules, and Lattice Sums of SiC With Wurtzite Structure. Phys. Rev., vol. 143, no. 2, Mar. 11, 1966, pp. 526-536.

6. Golightly, J. P.; and Beaudin, L. J.: Some Aspects of Disorder in Silicon Carbide. Silicon Carbide - 1968. Proceedings of the International Conference on Silicon Carbide. H. K. Henisch and R. Roy, eds., Pergamon Press, 1969, pp. S119S128.

7. Shaffer, P. T. B.: Use of the Microscope in the Observation and Identification of Silicon Carbide Structures. The Microscope, vol. 18, Third Qtr., July 1970, pp. 179-191.

8. Thibault, Newman W.: Morphological and Structural Crystallography and Optical Properties of Silicon Carbide (SiC). Amer. Mineral., vol. 29, nos. 9/10, Sept. Oct. 1944, pp. 327-362.

9. Shaffer, Peter T. B.: Refractive Index, Dispersion, and Birefringence of Silicon Carbide Polytypes. Appl. Opt., vol. 10, no. 5, May 1971, pp. 1034-1036. 
10. Golightly, J. P.: The Birefringence and Dichroism of Silicon Carbide Polytypes. Canadian Mineral., vol. 10, Pt. 1, 1969, pp. 105-108.

11. Powell, J. Anthony: Crystal Growth of $2 \mathrm{H}$ Silicon Carbide. J. Appl. Phys., vol. 40 , no. 11 , Oct. 1969 , pp. 4660-4662.

12. Bond, W. L.: Measurement of the Refractive Indices of Several Crystals. J. Appl. Phys., vol. 36, no. 5, May 1965, pp. 1674-1677.

13. Jenkins, Francis A.; and White, Harvey E.: Fundamentals of Optics. Third ed., McGraw-Hill Book Co., Inc., 1957.

14. Brafman, O.; and Steinberger, I. T.: Optical Band Gap and Birefringence of ZnS Polytypes. Phys. Rev., vol. 143, no. 2, Mar. 11, 1966, pp. 501-505. 
OFFICIAL BUSINESS

PENALTY FOR PRIVATE USE \$300
FIRST CLASS MAIL
POSTAGE AND FEES PAID NATIONAL AERONAUTICS AND SPACE ADMINISTRATION

007001 C1 U $26 \quad 720112$ S00903DS

DEPT OF THE AIR FORCE

AF VEAPONS LAB (AFSC)

TECH LIBR ARY/WLLL/

ATTN: E LOU BOWMAN, CHIEF

KIRTLAND AFB NM 87117

POSTMASTER: If Undeliverable (Section 158

"The aeronautical and space activities of the United States shall be conducted so as to contribute .. . to the expansion of human knowledge of phenomena in-the atmosphere and space. The Administration shall provide for the widest practicable and appropriate dissemination of information concerning its activities and the results thereof."

- National Aeronautics and SPaCe ACt OF 1958

-

\section{NASA SCIENTIFIC AND TECHNICAL PUBLICATIONS}

TECHNICAL REPORTS: Scientific and technical information considered important, complete, and a lasting contribution to existing knowledge.

TECHNICAL NOTES: Information less broad in scope but nevertheless of importance as. a contribution to existing knowledge.

TECHNICAL MEMORANDUMS: Information receiving limited distribution because of preliminary data, security classification, or other reasons.

CONTRACTOR REPORTS: Scientific and technical information generated under a NASA contract or grant and considered an important contribution to existing knowledge.
TECHNICAL TRANSLATIONS: Information published in a foreign language considered to merit NASA distribution in English.

SPECIAL PUBLICATIONS: Information derived from or of value to NASA activities. Publications include conference proceedings, monographs, data compilations, handbooks, sourcebooks, and special bibliographies.

TECHNOLOGY UTILIZATION PUBLICATIONS: Information on technology used by NASA that may be of particular interest in commercial and other non-aerospace applications. Publications include Tech Briefs, Technology Utilization Reports and

Technology Surveys.

Details on the availability of these publications may be obtained from:

SCIENTIFIC AND TECHNICAL INFORMATION OFFICE 